\title{
NONHOMOGENEOUS STOCHASTIC PROCESSES CONNECTED TO POISSON PROCESS
}

\section{Franciszek Grabski}

Polish Naval Academy, Faculty of Mechanical and Electrical Engineering, Śmidowicza 69 Str., 81-127 Gdynia, Poland; e-mail: f.grabski@amw.gdynia.pl

\begin{abstract}
Some generalizations of the Poisson process and their properties are presented in the paper. The nonhomogeneous Poisson process allows to construct a probabilistic model describing the different kinds of accidents number. The nonhomogeneous compound Poisson process enables to describe mathematically the various types of accidents consequences. Theoretical results give possibility to anticipate the accidents number and their consequences.
\end{abstract}

Key words:

nonhomogeneous Poisson process, nonhomogeneous compound Poisson process, safety characteristics.

(C) 2018 Franciszek Grabski This is an open access article licensed under the Creative Commons Attribution-NonCommercial-NoDerivatives 4.0 license (http://creativecommons.org/licenses/by-nc-nd/4.0/) 


\section{INTRODUCTION}

In 1837 Simeon-Denis Poisson derived this distribution to approximate the Binomial Distribution when a parameter $p$, determining the probability of success in a single experiment, is small. Application of this distribution was not found; when von Bortkiewitsch (1898) calculated from the data of the Prussian army the number of soldiers who died during the 20 consecutive years because of the kick by a horse. A random variable, say $X$, denoting the number of solders killed accidentally by the horse kick per year, turned out to have Poisson distribution

$$
p(k)=P(X=k)=\frac{(\Lambda)^{k}}{k !} e^{-\Lambda}, k \in \mathrm{S}=\mathbb{N}_{0}=\{0,1,2, \ldots\}
$$

with parameter $\Lambda=0.61\left[\frac{1}{y e a r}\right]$. We calculate several probabilities according to this distribution.

$$
\begin{gathered}
P(X=0)=0.543351, P(X=1)=0.331444, \\
P(X=2)=0.101090, \\
P(X=3)=0.020555, P(X=4)=0.003135, \\
P(X \leq 4)=0.999575, P(X>4)=0.000425 .
\end{gathered}
$$

It can be noticed, that the probability of no soldiers killed accidentally by the horse kick per year is over $50 \%$ and the probability that more then 4 solders was killed during the year is 0.000425 .

A nonhomogeneous Poisson process and nonhomogeneous compound Poisson process are generalizations of the Poisson process. The nonhomogeneous Poisson process allow to construct a probabilistic model describing the numbers of different types of accidents The nonhomogeneous compound Poisson process gives possibility to describe mathematically different kinds of the accidents consequences. Theoretical results presented in [1,3-7] enable to anticipate the accidents number and their consequences.

\section{HOMOGENUOUS POISSON PROCESS}

A random process $\{X(t): t \geq 0\}$ is said to be process with independent increments if for all $t_{1}, \ldots, t_{n}$ such that $0<t_{1}<t_{2}<\cdots<t_{n}$ the random variables $X(0), X\left(t_{1}\right)-X(0), \ldots, X\left(t_{n}\right)-X\left(t_{n-1}\right)$ are mutually independent. If the increments 
$X(s)-X(t)$ and $X(s+h)-X(t+h)$ for all $t, s, h>0, s>t$ have the identical probability distributions then $\{X(t): t \geq 0\}$ is called a process with the stationary independent increments (SII). It is proved that for the SII processes such that $X(0)=0$ an expectation and a variance are

$$
E[X(t)]=m_{1} t, V[X(t)]=\sigma_{1}^{2} t,
$$

where

$$
m_{1}=E[X(1)] \text { and } \sigma_{1}^{2}=V[X(1)] .
$$

An example of a SII random process is a Poisson process.

\section{Definition 1}

A stochastic process $\{X(t) ; t \geq 0\}$ taking values on $S=\mathbb{N}_{0}=\{0,1,2, \ldots\}$, with the right continuous and piecewise constant trajectories is said to be a Poisson process with parameter $\lambda>0$ if:

1. $X(0)=0$.

2. $\{X(t): t \geq 0\}$ is the process with the stationary independent increaments.

3. For all $t>0, h \geq 0$.

$$
P(X(t+h)-X(t)=k)=\frac{(\lambda h)^{k}}{k !} e^{-\lambda t}, k \in \mathbb{N}_{0} .
$$

For $t=0$ we get a first order distribution of the Poisson process:

$$
p_{k}(h)=P(X(h)=k)=\frac{(\lambda h)}{k !} e^{-\lambda h}, k \in \mathbb{N}_{0} .
$$

For $h=1$ we obtain the Poisson distribution with parameter $\lambda$. Hence $E[X(1)]=\lambda$ and $V[X(1)]=\lambda$. Therefore, from (1) and (2), we obtain the expectation and the variance of the Poisson process:

$$
E[X(t)]=\lambda t, V[X(t)]=\lambda t, t \geq 0 .
$$

For a fixed $t$ this formula determines the Poisson distribution with parameter $\Lambda=\lambda t$ :

$$
p(k)=P(X=k)=\frac{\Lambda^{k}}{k !} e^{-\Lambda}, k \in \mathbb{N}_{0} .
$$

\section{NONHOMOGENEOUS POISSON PROCESS}

We will begin with a reminder of the concept of nonhomogeneous Poisson's process.

2 (213) 2018 
Let

$$
\tau_{0}=\vartheta_{0}=0, \tau_{n}=\vartheta_{1}+\vartheta_{2}+\cdots+\vartheta_{n}, n \in \mathbb{N},
$$

where $\vartheta_{1}, \vartheta_{2}, \ldots, \vartheta_{n}$ are positive and independent random variables.

Let

$$
\tau_{\infty}=\lim _{n \rightarrow \infty} \tau_{n}=\sup \left\{\tau_{n}: n \in \mathbb{N}_{0}\right\} .
$$

A stochastic process $\{N(t): t \geq 0\}$ defined by the formula

$$
N(t)=\sup \left\{n \in \mathbb{N}_{0}: \tau_{n} \leq t\right\}
$$

is called a counting process corresponding to a random sequence $\left\{\tau_{n}: n \in \mathbb{N}_{0}\right\}$.

Let $\{N(t): t \geq 0\}$ be a stochastic process taking values on $S=\mathbb{N}_{0}=\{0,1,2, \ldots\}$, value of which represents the number of events in a time interval $[0, t]$.

\section{Definition 2}

A counting process $\{N(t): t \geq 0\}$ is said to be nonhomogeneous Poisson process (NPP) with an intensity function $\lambda(t) \geq 0, t \geq 0$, if

1. $P(N(0)=0)=1$.

2. The process $\{N(t): t \geq 0\}$ is the stochastic process with independent increments, the right continuous and piecewise constant trajectories.

3. $P(N(t+h)-N(t)=k)=\frac{\left(\int_{t}^{t+h} \lambda(x) d x\right)^{k}}{k !} e^{-\int_{t}^{t+h} \lambda(x) d x}$.

From this definition it follows that the one dimensional distribution of NPP is given by the rule

$$
P(N(t)=k)=\frac{\left(\int_{0}^{t} \lambda(x) d x\right)^{k}}{k !} e^{-\int_{0}^{t} \lambda(x) d x}, k=0,1,2, \ldots
$$

The expectation and the variance of NPP are the functions given by

$$
\begin{gathered}
\Lambda(t)=E[N(t)]=\int_{0}^{t} \lambda(x) d x ; \\
\mathrm{V}(t)=V[N(t)]=\int_{0}^{t} \lambda(x) d x, t \geq 0 .
\end{gathered}
$$

The corresponding standard deviation is

$$
\mathrm{D}(\mathrm{t})=\sqrt{V[N(t)]}=\sqrt{\int_{0}^{t} \lambda(x) d x}, t \geq 0 .
$$


The expected value of the increment $N(t+h)-N(t)$ is

$$
\Delta(t ; h)=E(N(t+h)-N(t))=\int_{t}^{t+h} \lambda(x) d x .
$$

The corresponding to it standard deviation is

$$
\sigma(t ; h)=\sqrt{\int_{t}^{t+h} \lambda(x) d x}
$$

An nonhomogeneous Poisson process with $\lambda(t)=\lambda, t \geq 0$ for each $t \geq 0$, is a regular Poisson process. For the Poisson process with parameter $\lambda$ the random variables $\vartheta_{1}, \vartheta_{2}, \ldots, \vartheta_{n}, n=2,3, \ldots$ are mutually independent and exponentially distributed with the identical parameter $\lambda$.

The Poisson process is a counting process which is generated by the random sequence $\left\{\tau_{n}: n \in \mathbb{N}_{0}\right\}$, where $\tau_{n}=\vartheta_{1}+\vartheta_{2}+\cdots+\vartheta_{n}, n \in \mathbb{N}$.

The increments of an nonhomogeneous Poisson process are independent, but not necessarily stationary. A nonhomogeneous Poisson process is a Markov process.

\section{COMPOUND POISSON PROCESS}

Let $\{N(t): t \geq 0\}$ be a Poisson proces with intensity $\lambda>0$ and $X_{1}, X_{2}, \ldots$ be sequence of independent and identically distributed (i.i.d.) random variables independent of $\{N(t): t \geq 0\}$. A stochastic process

$$
X(t)=X_{1}+X_{2}+\cdots+X_{N(t)}, t \geq 0
$$

is called a compound Poisson process (CPP).

The probability discrete distribution function of $\{N(t): t \geq 0\}$ at $k$ is

$$
p(k ; t)=P(N(t)=k)=\frac{(\lambda t)^{k}}{k !} e^{-\lambda t}, k=0,1,2, \ldots
$$

We quote a well-known result $[1,3]$.

If $E\left(X_{1}^{2}\right)<\infty$, then

1. $E[X(t)]=\lambda t E\left(X_{1}\right)$.

2. $V[X(t)]=\lambda t E\left(X_{1}^{2}\right)$.

The concepts and facts can be generalized. 


\section{Definition 3}

Let $\{N(t): t \geq 0\}$ be a nonhomogeneous Poisson process (NPP) with an intensity function $\lambda(t), t \geq 0$ such that $\lambda(t) \geq 0$ for $t \geq 0$, and $X_{1}, X_{2}, \ldots$ is a sequence of the independent and identically distributed (i.i.d.) random variables independent of $\{N(t): t \geq 0\}$. A stochastic process $\{X(t): t \geq 0\}$ determines by the formula

$$
X(t)=X_{1}+X_{2}+\cdots+X_{N(t)}, t \geq 0
$$

is said to be a nonhomogeneous compound Poisson process (NCPP).

\section{Proposition 1}

If $\{N(t): t \geq 0\}$ is a nonhomogeneous Poisson process (NPP) with an intensity function $\lambda(t), t \geq 0$ such that $\lambda(t) \geq 0$ for $t \geq 0$, then cumulative distribution function (CDF) of the nonhomogeneous compound Poisson process is given by the rule

$$
G(x, t)=I_{[0, \infty)}(x) e^{-\Lambda(t)}+\sum_{k=1}^{\infty} p(k ; t) F_{X}^{(k)}(x),
$$

where

$F_{X}^{(k)}(x)$ denotes the $k$-fold convolution of CDF of the random variables $X_{i}, i=1,2, \ldots$ and

$$
\begin{gathered}
p(k ; t)=\frac{(\Lambda(t))^{k}}{k !} e^{-\Lambda(t)}, t \geq 0, k=0,1, \ldots ; \\
\Lambda(t)=E[N(t)]=\int_{0}^{t} \lambda(x) d x
\end{gathered}
$$

is discrete probability distribution of NPP.

P r o of: Using total probability low we obtain cumulative distribution function (CDF) of NCPP.

$$
\begin{gathered}
G(x, t)=P(X(t) \leq x)=P\left(X_{1}+X_{2}+\cdots+X_{N(t)} \leq x\right)= \\
=\sum_{k=0}^{\infty} P\left(X_{1}+\cdots+X_{N(t)} \leq x \mid N(t)=k\right) P(N(t)=k)=\sum_{k=0}^{\infty} p(k ; t) F_{X}^{(k)}(x)= \\
=I_{[0, \infty)}(x) e^{-\Lambda(t)}+\sum_{k=1}^{\infty} p(k ; t) F_{X}^{(k)}(x) .
\end{gathered}
$$

This proposition is generalization of resultas presented in [1].

\section{Corollary 1}

If the random variables , $i=1,2, \ldots$ are absolutely continuous with density function $f_{X}(\cdot)$, then the density of NCPP is given by the rule

$$
g(x, t)=\sum_{k=1}^{\infty} p(k ; t) f_{X}^{(k)}(x), t>0,
$$

where $f_{X}^{(k)}(x)$ denotes $k$-fold convolution of the density function $f_{X}(x)$. 


\section{Example 1}

Let the random variables $X_{i}, i=1,2, \ldots$ have normal distrbution $N(m, \sigma)$. It means that a probabilility density function of $X_{i}=X$ is

$$
f_{X}(x)=\frac{1}{\sqrt{2 \pi} \sigma} e^{-\frac{(x-m)^{2}}{2 \sigma^{2}}}, \sigma>0, m \in(-\infty, \infty) \cdot x \in(-\infty, \infty) .
$$

The sum $X_{1}+X_{2}+\cdots+X_{k}$ has normal distribution $N(k m, \sqrt{k} \sigma)$. Hence it's density is $k$-fold convolution of the density function $f_{X}(x)$ given by (25):

$$
f_{X}^{(k)}(x)=\frac{1}{\sqrt{2 \pi} \sqrt{k} \sigma} e^{-\frac{(x-k m)^{2}}{2 k \sigma^{2}}}
$$

Therefore the density of NCPP given by (18) takes the form

$$
g(x, t)=\frac{1}{\sqrt{2 \pi} \sigma} \sum_{k=1}^{\infty} \frac{(\Lambda(t))^{k}}{\sqrt{k} k !} e^{-\Lambda(t)} e^{-\frac{(x-k m)^{2}}{2 k \sigma^{2}}}, x \neq 0, t>0 .
$$

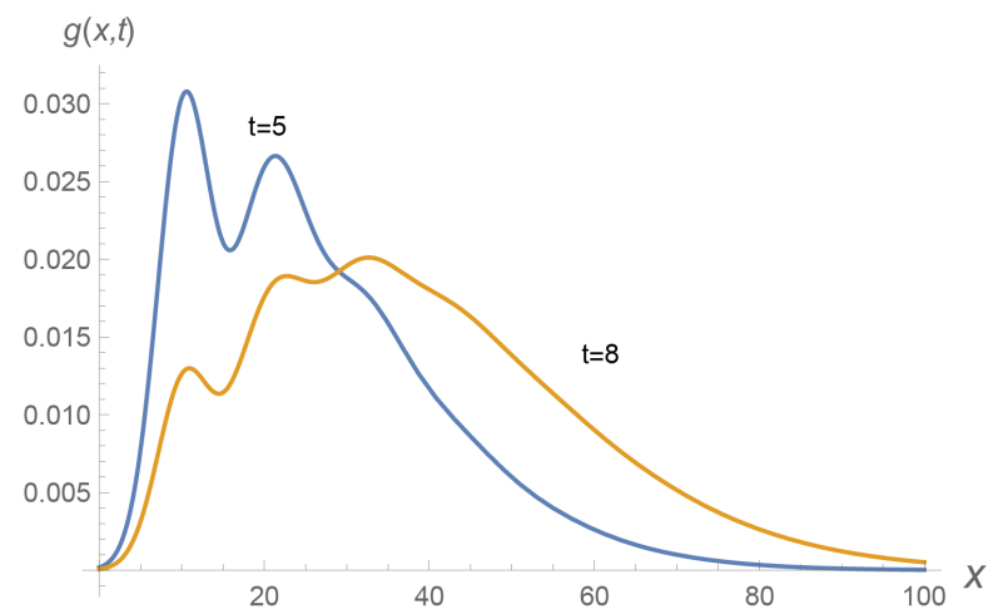

Fig. 1. The density functions of CPP for $\lambda=0.46, m=10.2, \delta=3.2$, and $t=5, t=8$

\section{Corollary 2}

If the random variables $X_{i}, i=1,2, \ldots$ are discrete distributed with probability function $p_{X}(x)=P(X=x), x \in S$ then the discrete probability distribution of NCPP is given by the rule

$$
g(x, t)=\sum_{k=1}^{\infty} p(k ; t) p_{X}^{(k)}(x), t>0
$$

where $p_{X}^{(k)}(x)$ denotes $k$-fold convolution of the discrete distribution function $p_{X}(x)$. 


\section{Example 2}

Assume that random variables $X_{i}, i=1,2, \ldots$ have a Poisson distribution with parameter $\mu>0$ :

$$
p_{X}(x)=\frac{\mu^{x}}{x !} e^{-\mu}, x=0,1,2, \ldots
$$

$k$-fold convolution of this discrete distribution functions is

$$
p_{X}^{(k)}(x)=\frac{(k \mu)^{x}}{x !} e^{-k \mu}, x=0,1,2, \ldots
$$

Then the rule (18) takes the form

$$
g(x, t)=\sum_{k=1}^{\infty} \frac{(\Lambda(t))^{k}}{k !} e^{-\Lambda(t)} \frac{(k \mu)^{x}}{x !} e^{-k \mu}, x=0,1,2, \ldots, t>0 .
$$

Assuming $\mu=0.064$ we comput probabilties (30). The results are shown in table 1 .

Tab. 1. The values of the function (30)

\begin{tabular}{|c|c|c|c|c|c|}
\hline$x$ & 0 & 1 & 2 & 3 & 4 \\
\hline$g(x, 40)$ & 0,133508 & 0,26032 & 0,262122 & 0,181373 & 0,0968526 \\
\hline$x$ & 5 & 6 & 7 & 8 & 9 \\
\hline$g(x, 40)$ & 0,0425101 & 0,0159536 & 0,00525922 & 0,00155298 & 0,00041687 \\
\hline
\end{tabular}

Fig. 2 shows a discrete probability distribution of a nonhomogeneous compound Poisson process under assumptions that random variables $X_{i}, i=1,2, \ldots$ have Poisson distribution with parameter $\mu=0.064$ and $t=40, \Lambda(40)=32,48$.

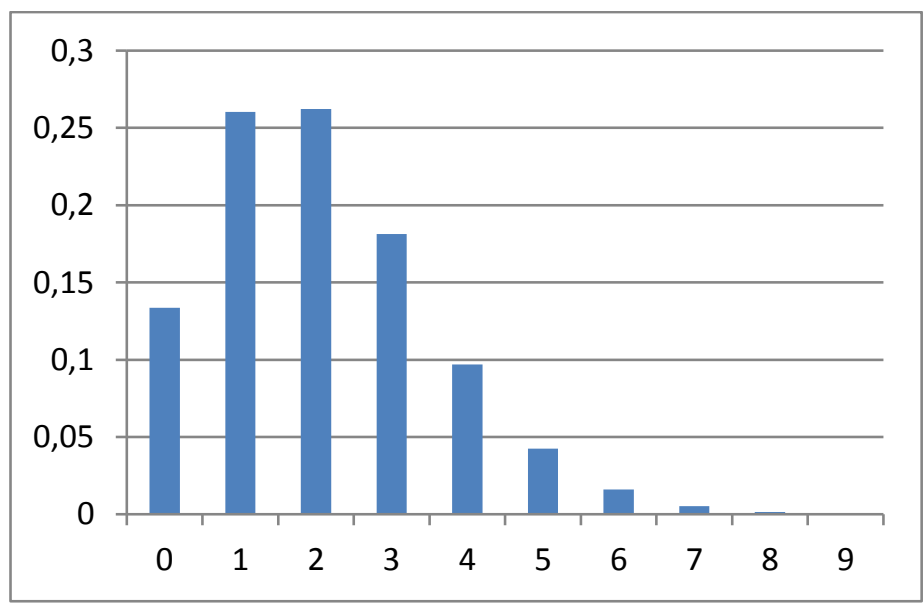

Fig. 2. A discrete probability distribution of NCPP corresponding to tab. 1 


\section{Proposition 2}

Let $\{X(t): t \geq 0\}$ be a nonhomogeneous compound Poisson process (NCPP).

If $E\left(X_{1}^{2}\right)<\infty$, then

1. $E[(t)]=\Lambda(t) E\left(X_{1}\right)$.

2. $V[X(t)]=\Lambda(t) E\left(X_{1}^{2}\right)$.

P r o of: Applying the property of conditional expectation

$$
E[X(t)]=E[E(X(t) \mid N(t))]
$$

we have

$$
\begin{gathered}
E[E(X(t) \mid N(t))]=E\left(E\left(X_{1}+X_{2}+\cdots+X_{N(t)}\right) \mid N(t)\right)= \\
=\sum_{n=0}^{\infty} E\left(X_{1}+X_{2}+\cdots+X_{N(t)} \mid N(t)=n\right) P(N(t)=n)= \\
=\sum_{n=0}^{\infty} E\left(X_{1}+X_{2}+\cdots+X_{n}\right) P(N(t)=n)= \\
=\sum_{n=0}^{\infty} E\left(X_{1}\right) n P(N(t)=n)=E\left(X_{1}\right) E(N(t)) .
\end{gathered}
$$

Using a formula

$$
V[X(t)]=E[V(X(t) \mid N(t))]+V[E(X(t) \mid N(t))]
$$

we get

$$
\begin{gathered}
=\sum_{n=0}^{\infty} V\left(X_{1}+X_{2}+\cdots+X_{N(t)} \mid N(t)=n\right) P(N(t)=n) \\
=\sum_{n=0}^{\infty} V\left(X_{1}+X_{2}+\cdots+X_{n}\right) P(N(t)=n)= \\
=\sum_{n=0}^{\infty} V\left(X_{1}\right) n P(N(t)=n)=V\left(X_{1}\right) E(N(t))=V\left(X_{1}\right) \Lambda(t) ; \\
V[E(X(t) \mid N(t))]= \\
=V\left(E\left(X_{1}+X_{2}+\cdots+X_{N(t))}\right) \mid N(t)\right)=V\left(E\left(X_{1}\right) N(t)\right)=\left(E\left(X_{1}\right)\right)^{2} V(N(t))= \\
=\left(E\left(X_{1}\right)\right)^{2} \Lambda(t) .
\end{gathered}
$$

Therefore

$$
\begin{gathered}
V[X(t)]=V\left(X_{1}\right) \Lambda(t)+\left(E\left(X_{1}\right)\right)^{2}=\Lambda(t)\left[E\left(X_{1}^{2}\right)-\left(E\left(X_{1}\right)\right)^{2}+\left(E\left(X_{1}\right)\right)^{2}\right]= \\
=\Lambda(t) E\left(X_{1}^{2}\right) .
\end{gathered}
$$

\section{Corollary 3}

Let $\{X(t+h)-X(t): t \geq 0\}$ be an increament of compound nonhomogeneous Poisson process (CNPP). 
If $E\left(X_{1}^{2}\right)<\infty$, then

$$
\begin{gathered}
E[X(t+h)-X(t)]=\Delta(t ; h) E\left(X_{1}\right) ; \\
D[X(t+h)-X(t)]=\sqrt{\Delta(t ; h) E\left(X_{1}^{2}\right)},
\end{gathered}
$$

where

$$
\Delta(t ; h)=\int_{t}^{t+h} \lambda(x) d x
$$

\section{CONCLUSIONS}

The results presented in the article are generalizations of theorems known in the literature. These generalizations concern increments of the nonhomogeneous Poisson process and increments of the nonhomogeneous compound Poisson process. The results allow to anticipate the number of different kinds of accidents and their consequences. The next paper will discuss application these theoretical results in modelling marine accidents $[2,5,8,9]$.

\section{REFERENCES}

[1] Andrzejczak K., Stochastic modeling of the repairable system, 'J. of KONBiN', 2015, No. 3(35).

[2] Annual report on Shipping accidents in the Baltic Sea 2013, HELCOM 2014.

[3] Di Crescenzo A., Martinucci B., Zacks S., Compound Poisson process with Poisson subordinator, 'Journal of Applied Probability', 2015, Vol. 52, No. 2, pp. 360-374.

[4] Fisz M., Probability and Mathematical Statistics [in Polish], PWN, Warsaw 1969.

[5] Grabski F., Nonhomogeneous Poisson process application to modelling accidents number at Baltic waters and ports, 'Journal of Polish Safety and Reliability Association', 2017, Vol. 8, No. 1, pp. 39-46.

[6] Grabski F., Semi-Markov models o reliability and operation [in Polish], IBS PAN Warsaw 2002.

[7] Grabski F., Semi-Markov Processes: Applications in Systems Reliability and Maintenance, Elsevier, Amsterdam - Boston - Heidelberg — London - NewYork - Oxford — Paris - San Diego San Francisco - Sydney 2015.

[8] Herdzik J., Zdarzenia wypadkowe na morzu i ich główne przyczyny, 'Autobusy', 2016, No. 10, pp. 33-38 [Accidents events at sea and their main causes - available in Polish].

[9] Limnios N., Oprisan G., Semi-Markov Processes and Reliability, Springer-Birkhauser, Boston 2001. 
[10] Shipping in the Baltic Sea - Past, present and future development relevant for Maritime Spatial Planning, Project Report I, Baltic LINes 2016.

[11] Shiryayev A. N., Probability, Springer-Verlag Berlin Heidelberg, New York — Tokyo 1984.

\section{NIEJEDNORODNE PROCESY STOCHASTYCZNE ZWIAZZANE Z PROCESEM POISSONA}

\section{STRESZCZENIE}

W artykule przedstawiono wybrane uogólnienia procesu Poissona i ich własności. Skupiono się na dwóch uogólnieniach - niejednorodnym procesie Poissona i niejednorodnym złożonym procesie Poissona. Niejednorodny proces Poissona pozwala na skonstruowanie modelu probabilistycznego opisującego liczbę różnych rodzajów wypadków. Niejednorodny złożony proces Poissona pozwala matematycznie opisywać konsekwencje tych wypadków. Przedstawione tu wyniki teoretyczne dają możliwość przewidywania liczby wypadków i ich konsekwencji.

\section{Słowa kluczowe:}

niejednorodny proces Poissona, niejednorodny złożony proces Poissona, charakterystyki bezpieczeństwa.

Article history

Received: 11.02.2018

Reviewed: 29.04.2018

Revised: 21.06.2018

Accepted: 22.06.2018 